\title{
Section properties of palm petioles, Part 1: The influence of section shape on the flexural and torsional properties of selected palm petioles
}

\author{
A.G.Windsor-Collins ${ }^{1}$, M.A.Atherton ${ }^{1}$, M.W.Collins ${ }^{1}$ \& \\ D.F.Cutler ${ }^{2}$ \\ ${ }^{1}$ School of Engineering \& Design, Brunel University, United Kingdom. \\ ${ }^{2}$ Royal Botanic Gardens, Kew, United Kingdom.
}

\begin{abstract}
Shape factors have been used to calculate the shape efficiency of palm leaf petiole sections in order to understand how palms compensate for the torsional and bending forces put upon them by their environment. That part of the palm leaf that is similar in form to the leaf stalk (petiole) in dicot leaves will be referred to as a petiole in this paper, whilst recognising that it is probably not an exact homologue. Wind and rain on the blade generate combined flexural and torsion loads on the petiole and a question arises as to how the section properties of the petiole deal with this loading. By isolating the shape from the size of the sections through the use of shape factors, the effects of the petiole section shape can be analysed on its own. Thus micro structural and material factors become a separate issue and will be discussed in a later paper. Cross section profiles from seven palm petioles are modelled, independent of their sizes, in order to calculate and plot the flexural and torsional coupling efficiencies for comparison with other plants and typical engineering cross sections.
\end{abstract}

Keywords: palm, petiole, vascular bundle, parenchyma, composite, torsion, flexural, cross section efficiency, evolution, shape factor, dicotyledon, monocotyledon 


\section{Introduction}

A common misconception of evolution is that it is said to 'progress' from 'lower' to 'higher' forms of life. The word 'progress' implies direction and improvement but neither are provided for by the mechanisms of evolution [1] and it is impossible to state any non-arbitrary criteria by which to measure 'progress'. Palms have been present for 65 million years [2] and yet remain relatively 'simple' in form and structure; they are not typically branched, have an adventitious root system and have primary rather than secondary thickening internally. The vascular bundles appear 'scattered' in transverse sections of the shoot, but have a complex and orderly spiralling arrangement in fact. Palms are classed as monocots (cf. monocotyledons) and as such have this characteristic arrangement of vascular bundles, whereas dicots (cf. dicotyledons), the other group comprising the flowering plants, frequently have a single, ring of vascular bundles towards the periphery that become joined by cambial tissue, enabling the stems to grow in thickness (secondary thickening). They are often branched (as are many other monocots) and have primary roots which may also become secondarily thickened.

In the context of engineering, the petiole can be described as a cantilevered beam and as such is subjected to bending and torsion loads in its natural habitat as shown in Fig 1. Both of these actions on the leaf may occur simultaneously and so the ratio of bending stiffness to torsional stiffness is a shape performance measure of interest.

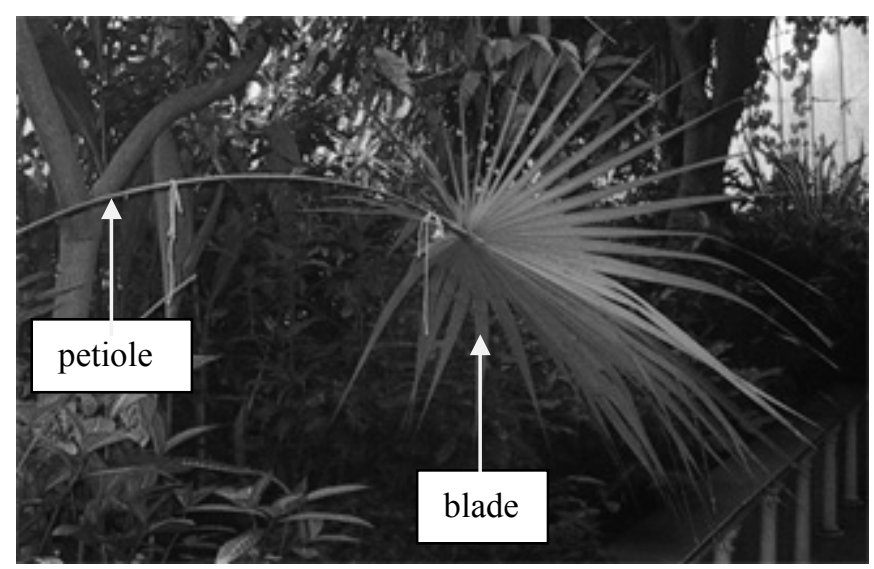

Figure 1: The leaf blade and petiole of the palm Thrinax morrisii.

Palm petioles taper in cross section lengthways, from trunk to leaf, usually having a groove running along the top (adaxial) surface and often only symmetrical about the vertical plane. Pasini \& Mirjalili [3] report that such a shape (for a dicot leaf petiole) allows the petiole to be less stiff when twisted while still maintaining its (downward) bending stiffness. Further, the groove 
allows the leaves to bunch together reducing wind drag and reducing the need for bending stiffness as through twisting, the petiole can orientate downwind to maximise wind spillage over its leaf.

The tapering of tree branches produces a uniform stress distribution in the outer fibres, ensuring efficient use of material [4], which leads us to expect that the petiole form will also adopt uniform stress distributions. In a later paper, we will consider how the internal structure and micro components of the petiole contribute to stress distributions.

Milwich et al [5] state that at least four structural gradients exist in plants on different hierarchal levels; the vascular bundles, the fibre caps and the parenchyma (relatively structurally weak matrix in which the former are embedded). Fig 2 shows how these components act together as a composite structure. It appears therefore that we need to look both at the individual hierarchal stress systems individually and as a whole in order to understand the petiole structure in its entirety.

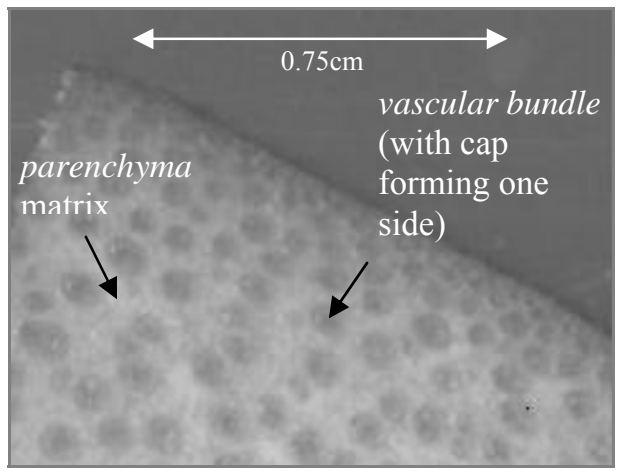

Figure 2: Part of palm petiole cross section showing vascular bundles and parenchyma matrix.

In this paper, cross section shape factors are examined through considering the petiole profiling data for seven individual palm species acquired from the Royal Botanical Gardens, Kew. Section shapes of the petiole vary from being grooved nearest the trunk to either angular, cylindrical or rhombohedral towards the distal end [6] making the theoretical analysis of these organic forms more complex than regular shaped bodies. As the cross section of the petiole varies along its length, profiles are acquired at three equidistant points along the petiole axis in order to determine section properties using a CAD system. Pasini \& Mirjalili [3] acquired the petiole cross section results for ten dicots and compared these with idealised ellipse and semi ellipse shapes to make an analysis of shape efficiency.

A way of measuring the structural performance of the petiole is to compare torsion flexibility with bending resistance. To calculate the efficiency of the petiole section shapes, a performance index is used based on the ratio of flexural 
to torsional shape stiffness [3], the index being highest when the torsion flexibility is maximised for a given flexural stiffness.

The petiole cantilever is unlike a typical manmade structure in which both the resistance to torsion and bending are maximised in order to produce a rigid structure. In the case of the petiole, the bending resistance is maximised and torsional resistance minimised, which maximises the performance index, $p$, in Equation 1.

$\mathrm{p}=\mathrm{EI} / \mathrm{GJ}=\mathrm{EI}_{\mathrm{D}} \Psi_{\mathrm{I}} / \mathrm{GJ}_{\mathrm{D}} \Psi_{\mathrm{J}}$

where $E$ is the Young's modulus, I is the second moment of area, G is the torsional rigidity modulus, $\mathrm{J}$ is the polar second moment of area, $\mathrm{I}_{\mathrm{D}}$ is the second moment of area of the rectangular envelope, $\Psi_{\mathrm{I}}$ is the shape factor for the second moment of area, $\mathrm{J}_{\mathrm{D}}$ is the polar second moment of area of the rectangular envelope and $\Psi_{\mathrm{J}}$ is the shape factor for the polar second moment of area.

The shape factor for a petiole of cross sectional area A, corresponds to the smallest rectangle, $A_{D}$, that will enclose its shape. The shape factors are defined as follows:
Area:
$\psi_{\mathrm{A}}=\mathrm{A} / \mathrm{A}_{\mathrm{D}}$
Second moment of area:
$\psi_{\mathrm{I}}=\mathrm{I} / \mathrm{I}_{\mathrm{D}}$
Polar second moment of area:
$\psi_{\mathrm{J}}=\mathrm{J} / \mathrm{J}_{\mathrm{D}}$

While this method has been applied to dicot plants by Pasini \& Mirjalili [3], within our knowledge, this is the first time it has been applied to palms (monocots).

\section{Petiole section shape efficiency}

\subsection{Acquisition of palm petiole data}

A data sheet pro-forma was created to ensure consistent procedures were followed when acquiring the petiole data. As it was often wet after watering of the palms in the morning and difficult to acquire the data, this made the procedures more important.

Palms that were within easy reach of measurement were selected in terms of height and closeness to the side of the bedding plot and photographs of each of the palms from which data were acquired are shown in Figure 3. Of the palms measured, all were mature as each had developed stems (juvenile palms have a crown but little or no stem and may have different properties to mature specimens). Since disease on the petioles can affect the structural properties of the palm, it was necessary to check for its absence. This was done with the naked eye. The petioles were free from contact with any other vegetation so that their development had not been influenced by external forces. However, it must be pointed out that these palms were not grown in their natural habitat and as such have not strengthened in response to natural external environmental forces. The palm species selected were Sabal minor (Jacq.) Pers.; Thrinax morrisii (H. 
Wendl.); Latania vershaffeltii (Lem.); Pritchardia kaalae (Rock.); Kerriodoxa elegans Dransfield; Borassodendron machadonis (Ridley) Becc. and Trachycarpus fortunei (Hook.) H. Wendl and these are shown in Figs 3 (a) - (g). The T. fortunei palm was the only palm tested which grew outside the Palm House at the Royal Botanic Gardens, Kew. However, it was partially sheltered from external forces by buildings and other trees as shown in Figure 3(g). 


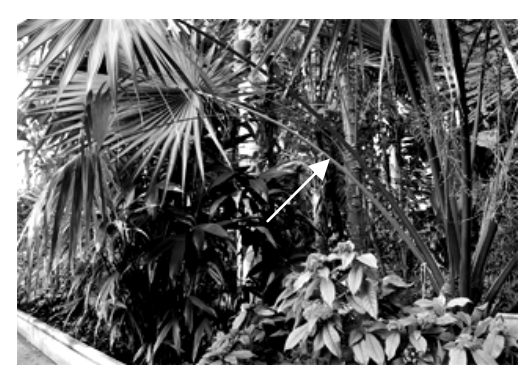

(a) S. minor

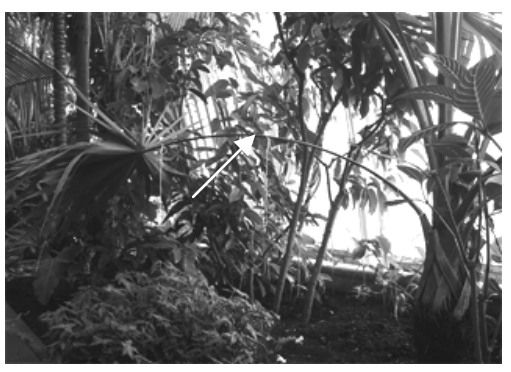

(b) T. morrisii

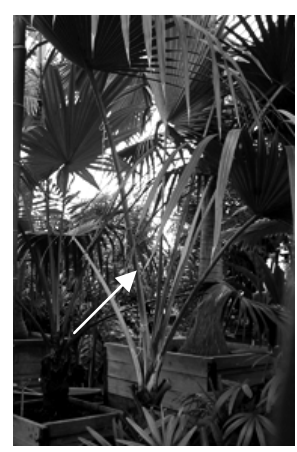

(c) L. vershaffeltii

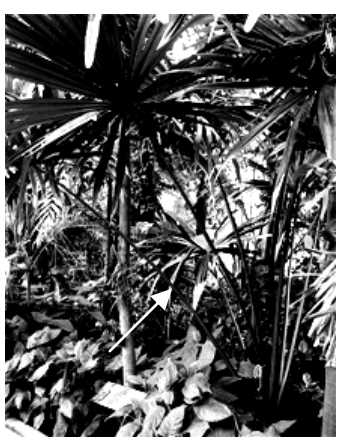

(d) B. machadonis

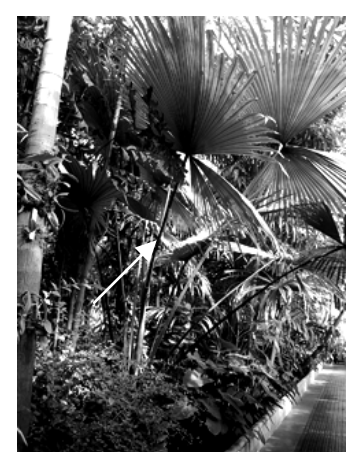

(e) K. elegans

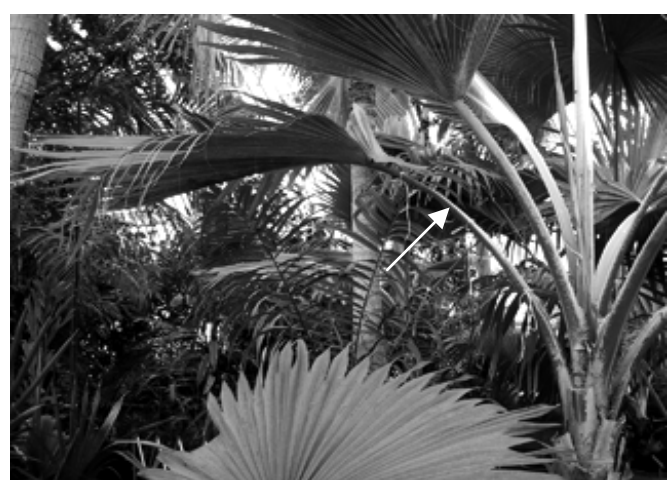

(f) P. kaalae

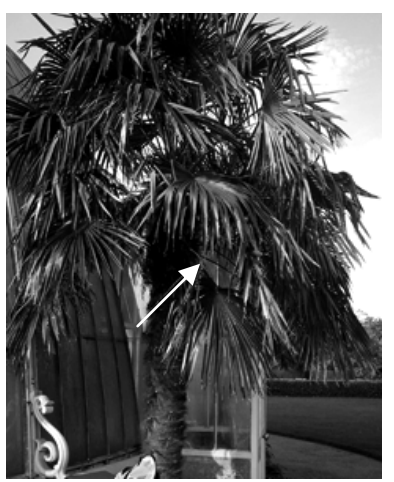

(g) T. fortunei

Figure 3: Photographs of the palms from which profiling data were acquired. 
A record was made of the blade type (pinnate, palmate), width and length (beyond the hastula as shown in Fig. 4) together with the angle that both the proximal and distal parts of the petiole made with the trunk. The petiole length was measured from the hastula to a point in line with the petiole axis and $10 \mathrm{~cm}$ from the trunk.

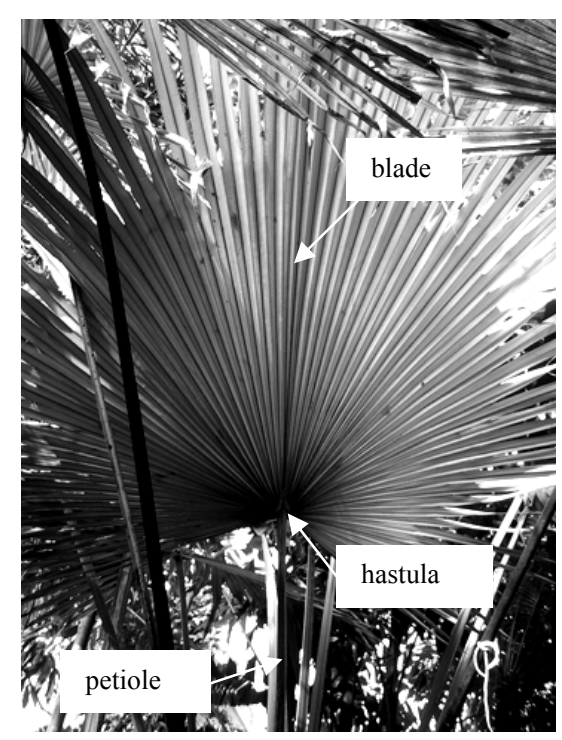

Figure 4: Blade and petiole of the palm K. elegans showing the location of the hastula.

Petiole cross section profiles were obtained using the profiler (Fig. 5) as close to the ends of the petiole as was practicable. Three profiles were recorded at equidistant points, $\mathrm{M}, \mathrm{N}$ and $\mathrm{O}$ as shown in Fig. 6. The trunk circumference and the height of the petiole above the ground were also recorded.

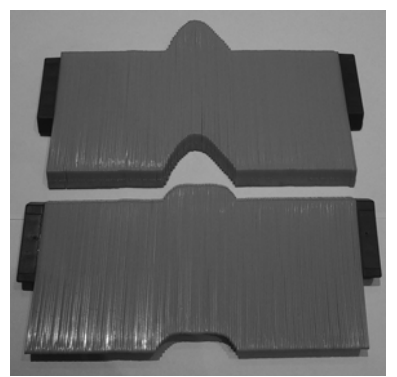

Figure 5: The profiling equipment used to measure the section shape of the petioles. 


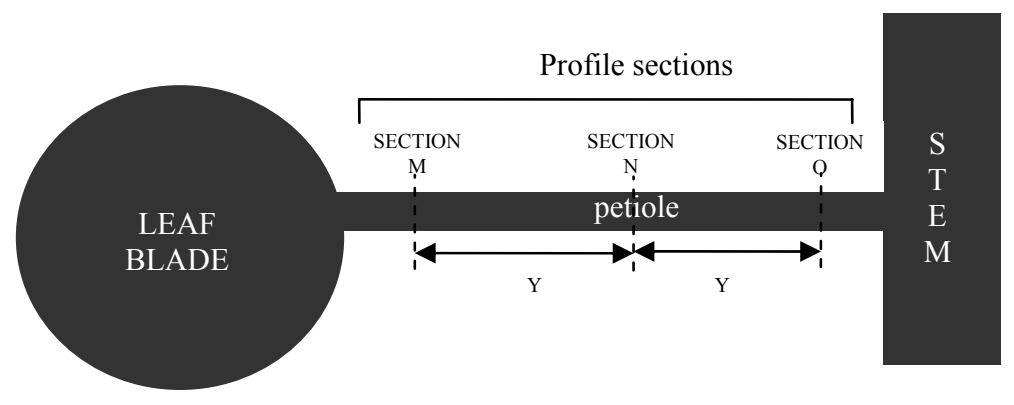

Figure 6: Schematic of palm blade, petiole and stem showing the relative positions of the profile samples

Three or four petioles were sampled from each palm to check for consistency and confidence intervals calculated. An example of the profiles for one petiole from K. elegans is shown in Figure 7.

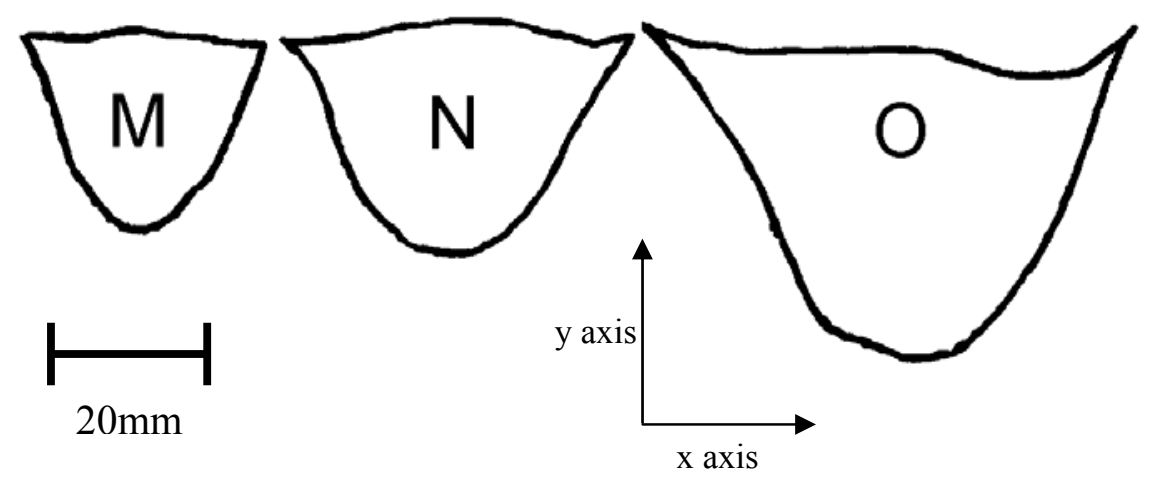

Figure 7: Profiles M, N \& O from one of four petioles from the palm K. elegans.

\subsection{Petiole shape factors}

The profiles were scanned and transcribed into a CAD package (Rhinoceros ${ }^{\circledR}$ NURBS modelling for Windows) enabling the area, centroid, second moment of area and polar second moment of area to be processed accurately. These models were then transformed into dimensionless geometrical shape factors [7], thereby normalising the section shape of the petiole.

To test the procedure, some of these properties were calculated manually. The profile images were rotated as much as possible to make the adaxial surface symmetrical about the y axis (Fig. 7) and promote accurate vertical flexural shape stiffness calculations. All records were discarded for palms for which it was only possible to collect one or two petiole samples. Three different petioles 
were measured for each palm apart from K.elegans from which four were tested and the sample mean averages of their parameters calculated. The standard deviations of the sample mean section shape factors are displayed in Table 1 and the confidence intervals are shown on the relevant subsequent plots. The largest standard deviation values are a result of natural variability rather than measurement error. Only data from the three palms which later show the most extreme parameters are displayed in Table 1.

\begin{tabular}{|l|l|l|l|l|l|l|l|l|l|}
\hline & $\mathrm{M}$ & $\mathrm{M}$ & $\mathrm{M}$ & $\mathrm{N}$ & $\mathrm{N}$ & $\mathrm{N}$ & $\mathrm{O}$ & $\mathrm{O}$ & $\mathrm{O}$ \\
\hline & $\begin{array}{l}\text { SD of } \\
\text { sample } \\
\text { mean } \\
\Psi_{\mathrm{a}}\end{array}$ & $\begin{array}{l}\mathrm{SD} \text { of } \\
\text { sample } \\
\mathrm{mean} \Psi_{\mathrm{i}}\end{array}$ & $\begin{array}{l}\text { SD of } \\
\text { sample } \\
\text { mean } \\
\Psi_{\mathrm{j}}\end{array}$ & $\begin{array}{l}\text { SD of } \\
\text { sample } \\
\text { mean } \\
\Psi_{\mathrm{a}}\end{array}$ & $\begin{array}{l}\text { SD of } \\
\text { sample } \\
\text { mean } \\
\psi_{\mathrm{I}}\end{array}$ & $\begin{array}{l}\text { SD of } \\
\text { sample } \\
\text { mean } \\
\Psi_{\mathrm{J}}\end{array}$ & $\begin{array}{l}\text { SD of } \\
\text { sample } \\
\text { mean } \\
\Psi_{\mathrm{A}}\end{array}$ & $\begin{array}{l}\text { SD of } \\
\text { sample } \\
\text { mean } \\
\psi_{\mathrm{I}}\end{array}$ & $\begin{array}{l}\text { SD of } \\
\text { sample } \\
\text { mean } \\
\psi_{\mathrm{J}}\end{array}$ \\
\hline P. kaalae (5) & .027 & .013 & .038 & .053 & .051 & .049 & .026 & .025 & .025 \\
\hline $\begin{array}{l}\text { Latania } \\
\text { verschaffeltii } \\
(4)\end{array}$ & .046 & .037 & .064 & .050 & .050 & .057 & .055 & .062 & .056 \\
\hline $\begin{array}{l}\text { K. elegans } \\
(11)\end{array}$ & .044 & .030 & .039 & .028 & .024 & .040 & .047 & .053 & .055 \\
\hline
\end{tabular}

Table 1: Standard deviations of sample mean section shape factors

\subsection{Petiole flexural shape stiffness}

\subsubsection{Palm petiole flexural shape stiffness: comparison with dicotyledons}

Figure 8 shows that the shape resistance to bending is progressively greater travelling from the stem (Section O) to the blade (Section M). The dicot data acquired by Pasini \& Mirjalili [3] were acquired nearest the stem node which corresponds to Section $\mathrm{O}$ on the palm petiole. With respect to petiole shape factors at the stem node, the dicot petioles had higher resistance to bending than the palms in general. The palm petioles became proportionally stiffer towards the leaf blade. 


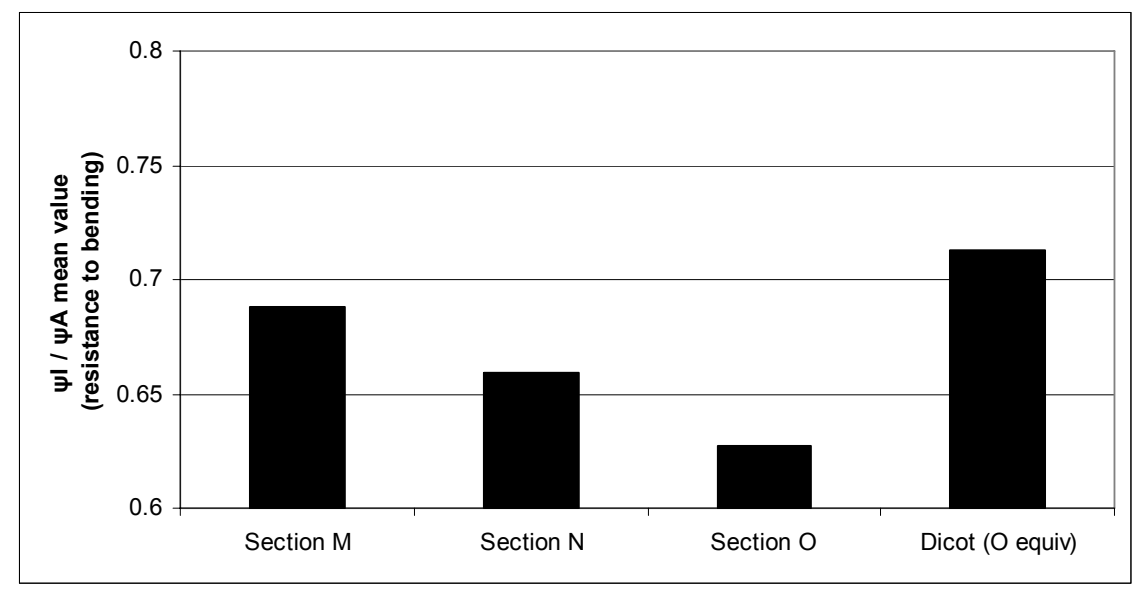

Figure 8: Mean $\psi_{\mathrm{I}} / \psi_{\mathrm{A}}$ (indicating resistance to bending) values for all of the palm petioles tested compared to dicot plant petioles.

Shape resistance to bending values of the petioles K. elegans, P. kaalae and L. vershaffeltii were calculated for all sample specimens (see Table 2) and the sample mean values are plotted in Figure 8.

Table 2: Mean $\psi_{\mathrm{I}} / \psi_{\mathrm{A}}$ (resistance to bending) values of each section $\mathrm{M}, \mathrm{N} \& \mathrm{O}$ along the petiole for samples A, B, C \& D for palms K. elegans, L.vershaffeltii and P.kaalae.

\begin{tabular}{|l|l|l|l|l|}
\hline Palm & Petiole & $\begin{array}{l}\text { Section } \mathrm{M} \\
\psi \mathrm{l} / \Psi \mathrm{A} \\
\text { value }\end{array}$ & $\begin{array}{l}\text { Section N } \\
\psi \mathrm{I} / \Psi \mathrm{A} \\
\text { value }\end{array}$ & $\begin{array}{l}\text { Section } \mathrm{O} \\
\psi \mathrm{l} / \Psi \mathrm{A} \\
\text { value }\end{array}$ \\
\hline K.elegans & Petiole A & 0.80 & 0.70 & 0.74 \\
\hline K.elegans & Petiole B & 0.73 & 0.72 & 0.70 \\
\hline K.elegans & Petiole C & 0.78 & 0.74 & 0.78 \\
\hline K.elegans & Petiole D & 0.81 & 0.73 & 0.78 \\
\hline L.vershaffeltii & Petiole A & 0.73 & 0.72 & 0.57 \\
\hline L.vershaffeltii & Petiole B & 0.73 & 0.75 & 0.63 \\
\hline L.vershaffeltii & Petiole C & 0.71 & 0.71 & 0.50 \\
\hline P. kaalae & Petiole A & 0.60 & 0.53 & 0.53 \\
\hline P. kaalae & Petiole B & 0.60 & 0.58 & 0.46 \\
\hline P. kaalae & Petiole C & 0.62 & 0.47 & 0.51 \\
\hline
\end{tabular}




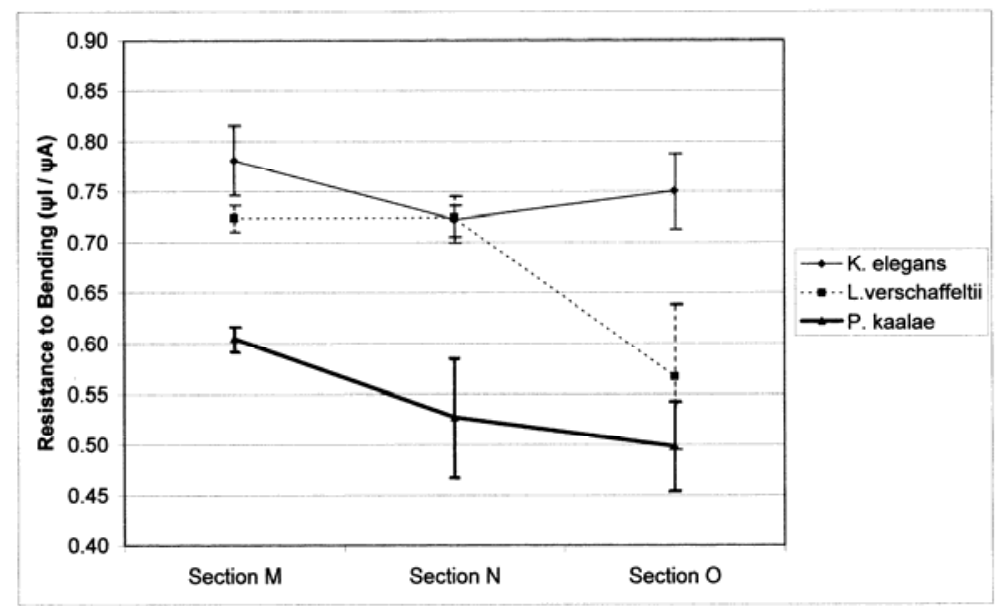

Figure 9: Palms with the highest and lowest values of mean resistance to bending showing 95\% confidence intervals. The 95\% confidence intervals are based on four samples.

Figure 9 shows that mean $\psi \mathrm{I} / \psi \mathrm{A}$ shape bending resistance values for $K$. elegans is higher at the blade end (position $\mathrm{M}$ ) than at the centre (position $\mathrm{N}$ ).

Mean $\psi \mathrm{I} / \psi \mathrm{A}$ values for $L$. vershaffeltii show a relatively low resistance to bending at the trunk end (position $\mathrm{O}$ ) compared with positions $\mathrm{M}$ and $\mathrm{N}$.

Compared to $K$. elegans and $L$. vershaffeltii, the mean $\psi_{\mathrm{I}} / \psi_{\mathrm{A}}$ values of $P$. kaalae display the lowest bending shape stiffness along the entire length of the petiole. Along the petiole, it also has the most resistance to bending at the blade end (Section M).

\subsubsection{Flexural shape stiffness of palm petiole cross sections versus elliptical and semi-elliptical shapes}

We are now in a position to present these results in engineering terms. In shaperelated structural analysis we define two distinct classes; ellipsoid and semiellipsoid, each of which has solid and hollow alternatives. The formulae for these are given in Table 3 and are used to calculate boundaries defining those areas in Figs 10-12. Also the solid/hollow alternatives as indicated within this engineering scheme are presented. 
Table 3: Shape transformer formulae used for elliptical and semi-elliptical boundary curves shown in Figures 10 to 12

\begin{tabular}{|l|l|l|}
\hline Cross section shape & $\psi_{\mathrm{I}}$ & $\psi_{\mathrm{J}}$ \\
\hline Solid ellipse & $3 \pi / 16$ & $3 \pi / 16$ \\
\hline Hollow ellipse & $(3 / 2) \psi_{\mathrm{A}}\left[1-(2 / \pi) \psi_{\mathrm{A}}\right]$ & $(3 / 2) \psi_{\mathrm{A}}\left[1-(2 / \pi) \psi_{\mathrm{A}}\right]$ \\
\hline Solid semi-ellipse & 0.66 & $0.66 \sin ^{2}(\alpha)+(3 \pi / 16) \cos ^{2}(\alpha)$ \\
\hline Hollow semi-ellipse & $0.66\left[1-\left(1-4 \psi_{\mathrm{A}} / \pi\right)^{2}\right]$ & $\psi_{\mathrm{I}}\left[\sin ^{2}(\alpha)+(\pi / 3.52) \cos ^{2}(\alpha)\right]$ \\
\hline
\end{tabular}

Different $\psi_{\mathrm{I}} / \psi_{\mathrm{A}}$ values indicate the fraction \& placement of material within the envelope [3]. Figures 10 to 12 show how seven of the tested palm petioles compare in terms of bending shape resistance.

According to Figure 10, for section M nearest the blade, K. elegans has the most resistance to bending $(\psi \mathrm{I} / \psi \mathrm{A})$ of the palms although all the palm samples were more resistant to bending than the solid elliptical and semi-elliptical sections of the same $\psi \mathrm{A}$. At the opposite extreme, T. morrisii showed the most flexural bending and had the same resistance to bending as the corresponding solid semi-ellipse with the same $\psi \mathrm{A}$.

For the middle section $\mathrm{N}$ it can be seen in Figure 11 that T. morrisii had the same $\psi_{\mathrm{I}} / \psi_{\mathrm{A}}$ as the corresponding solid semi ellipse with the same $\psi \mathrm{A}$. The remainder of the palms had more resistance to bending compared to the corresponding solid semi ellipse with the same $\psi \mathrm{A}$ but still less than the hollow ellipse and semi-ellipse shapes.

For section $\mathrm{O}$ nearest the trunk it can be seen in Figure 12 that Latania verschaffeltii was found to have the same resistance to bending as the corresponding solid ellipse with the same $\psi \mathrm{A}$; less than all of the solid semi ellipses and other palms. K. elegans and $T$. fortunei had the most resistance to bending compared to the other palms and corresponding solid semi ellipse and ellipse shapes with the same $\psi \mathrm{A}$. 


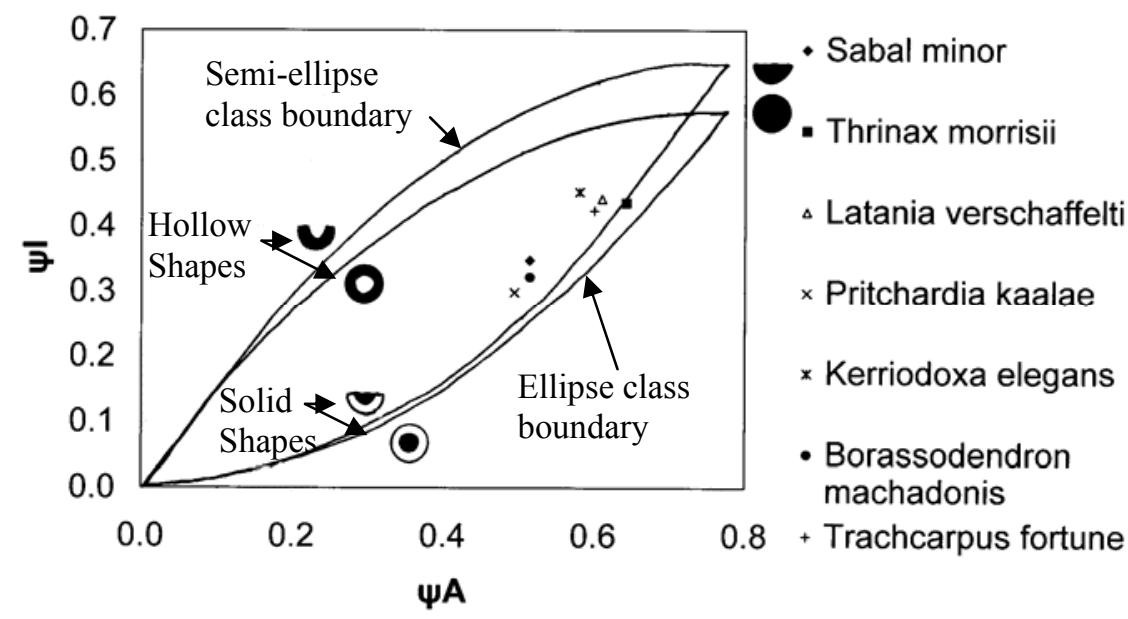

Figure 10: Section M mean flexural shape stiffness for palm specimens, ellipsoid and semi-ellipsoid shapes.

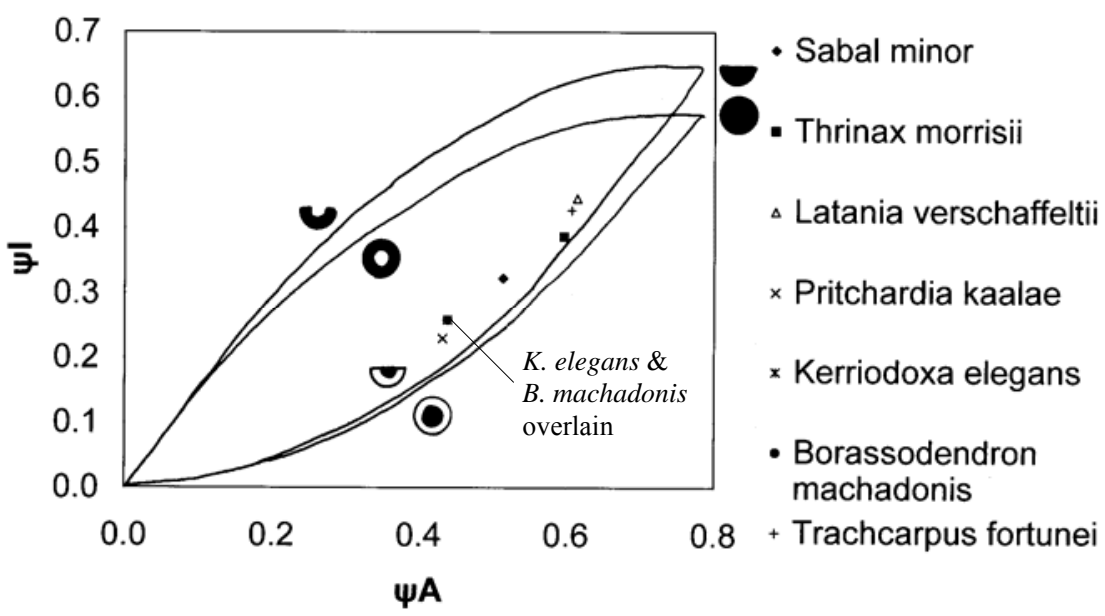

Figure 11: Section $\mathrm{N}$ mean flexural shape stiffness for palm specimens, ellipsoid and semi-ellipsoid shapes. 


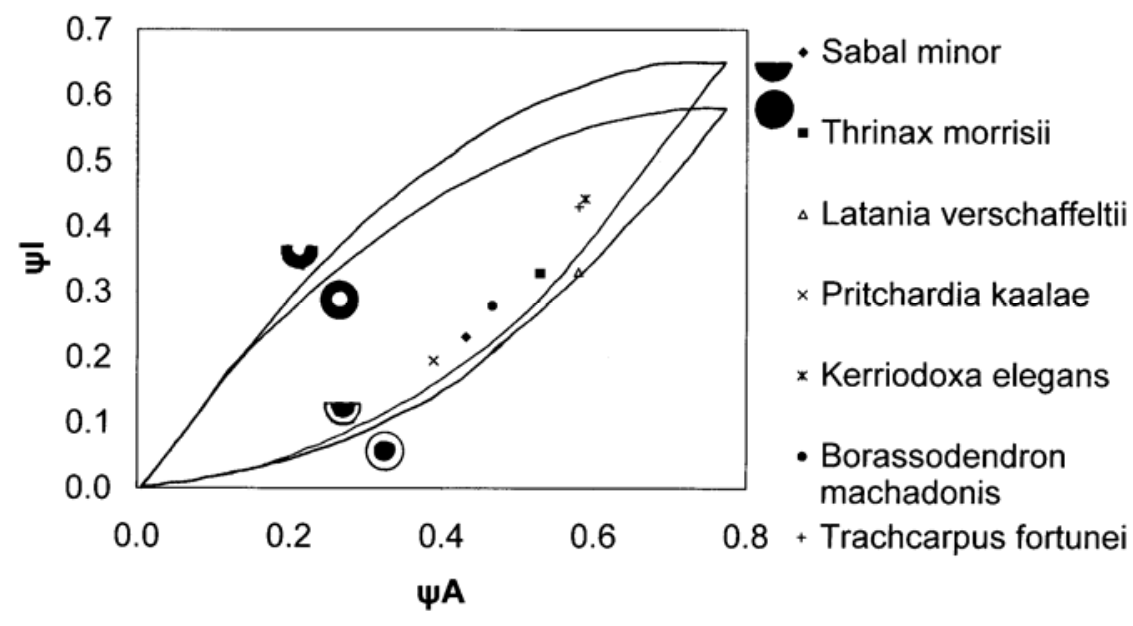

Figure 12: Section O mean flexural shape stiffness for palm specimens, ellipsoid and semi-ellipsoid shapes.

\subsubsection{Flexural shape stiffness conclusions}

From the above it is seen that generally petiole shape becomes proportionally stiffer (in terms of second moment of area) towards the leaf blade and is more flexible than the dicot petioles acquired by Pasini \& Mirjalili [3]. The palm petioles are more efficient with respect to shape bending factors than the solid elliptical and semi-elliptical shapes, but less efficient than the hollow corresponding shapes.

It is important to understand how each of the three sections (M, N \& O) of the petiole work together. The highest and lowest resistance to bending values of the palms were found in K. elegans, P. kaalae and L. vershaffeltii.

$K$. elegans had a higher resistance to bending at the blade end compared with the central position N. Compared with all of the other palms tested, P. kaalae had the weakest resistance to bending. Its shape stiffness was found to be proportional to distance from the leaf blade where it displayed the most resistance to bending.

L. vershaffeltii showed high average resistance to bending in Sections $\mathrm{M}$ and $\mathrm{N}$ which then significantly drops towards Section $\mathrm{O}$ nearest the trunk where it showed maximum flexibility. K. elegans and $T$. fortunei had the most resistance to bending compared to the other palms and corresponding solid semi ellipse and ellipse shapes of the same $\psi \mathrm{A}$.

The same sections were then investigated to see how they reacted to torsion. 


\subsection{Torsional shape stiffness}

\subsubsection{Palm petiole torsional shape stiffness: comparison with dicotyledons}

The dicot data were taken nearest the stem node which corresponds to Section $\mathrm{O}$ on the palm petiole. Figure 13 shows that at the stem node, the mean averages of the dicot petioles had significantly higher shape resistance to torsion than all sections ( $\mathrm{M}, \mathrm{N}$ and $\mathrm{O}$ ) for the palms. The torsional shape stiffness median values for each palm section had similar values to each other.

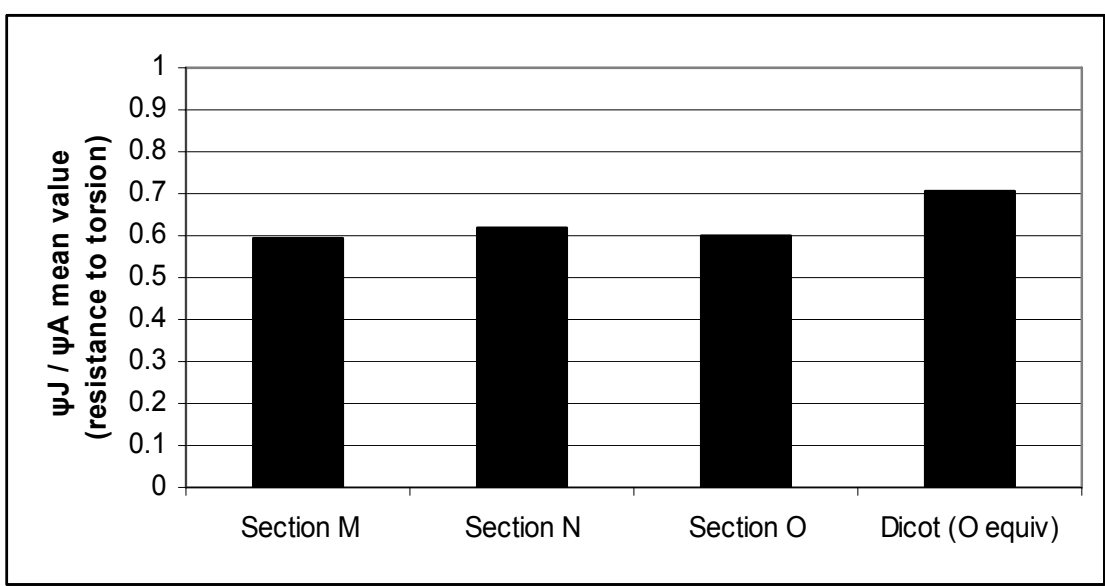

Figure 13: Comparison of mean $\psi_{\mathrm{J}} / \psi_{\mathrm{A}}$ (resistance to torsion) values for all palm petioles sections tested and for the dicot plant petioles.

Shape resistance to torsion values of the petioles K. elegans, P. kaalae and $L$. vershaffeltii were calculated for all sample specimens as shown in Table 4 with mean values being plotted in Figure 14. The highest and lowest shape resistance to torsion values of the palms were found in $K$. elegans, $P$. kaalae and $L$. vershaffeltii. 
Table 4: Mean $\psi_{\mathrm{I}} / \psi_{\mathrm{A}}$ (resistance to torsion) values for samples A, B and C and all sections for palms K.elegans, L.vershaffeltii and P.kaalae

\begin{tabular}{|c|c|c|c|c|}
\hline Palm & Petiole & $\begin{array}{l}\text { Section M } \\
\psi J / \psi A \\
\text { value }\end{array}$ & $\begin{array}{l}\text { Section } N \\
\psi J / \psi A \\
\text { value }\end{array}$ & $\begin{array}{l}\text { Section } O \\
\psi \mathrm{J} / \psi \mathrm{A} \\
\text { value }\end{array}$ \\
\hline K.elegans & Petiole A & 0.59 & 0.65 & 0.65 \\
\hline K.elegans & Petiole B & 0.63 & 0.56 & 0.53 \\
\hline K.elegans & Petiole C & 0.59 & 0.63 & 0.62 \\
\hline K.elegans & Petiole D & 0.63 & 0.63 & 0.60 \\
\hline L.vershaffeltii & Petiole A & 0.70 & 0.61 & 0.74 \\
\hline L.vershaffeltii & Petiole B & 0.59 & 0.66 & 0.67 \\
\hline L.vershaffeltii & Petiole C & 0.61 & 0.58 & 0.67 \\
\hline P.kaalae & Petiole A & 0.61 & 0.58 & 0.59 \\
\hline P.kaalae & Petiole B & 0.59 & 0.56 & 0.54 \\
\hline P.kaalae & Petiole C & 0.51 & 0.47 & 0.55 \\
\hline
\end{tabular}

Mean $\psi \mathrm{J} / \psi \mathrm{A}$ values for the three palms showed that $L$. vershafeltii had the highest resistance to torsion for section $\mathrm{O}$ nearest the trunk.

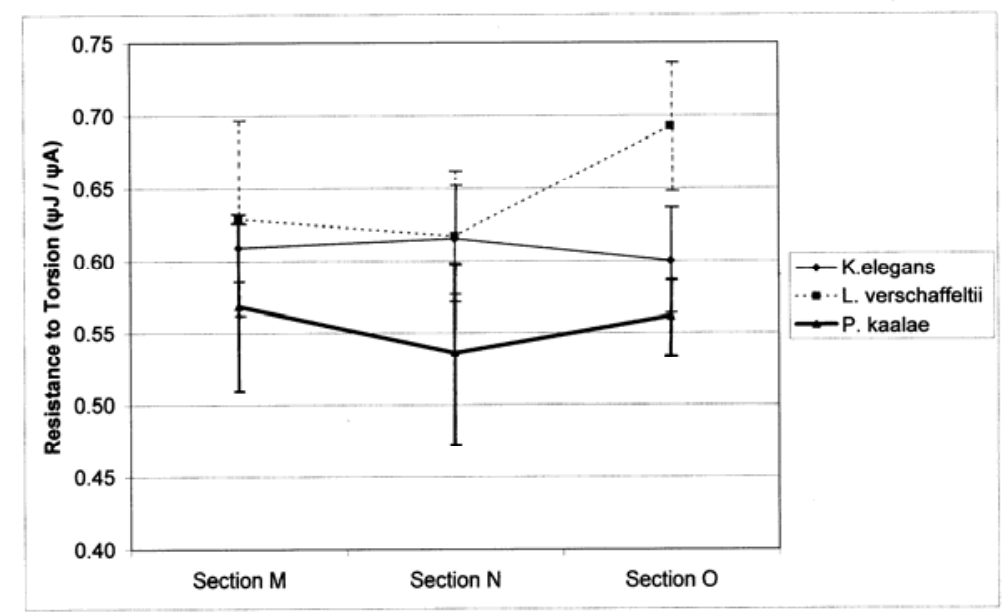

Figure 14: Palms with the highest and lowest values of mean resistance to torsion showing $95 \%$ confidence intervals. 
2.4.2 Torsional shape stiffness of palm petiole: comparison with engineered semi-ellipsoid and ellipsoid shape cross sections

Figures $15-17$ shows the mean torsional shape stiffness for palm specimens, for sections $\mathrm{M}, \mathrm{N}$ and $\mathrm{O}$ respectively in comparison to the ideal ellipsoid and semiellipsoid shapes. The ellipse and semi-ellipse shapes are equally resistant to torsion [3]. The palms have similar resistance to torsion as the solid ellipses and semi-ellipses but are more efficient in terms of the $p$ factor as specified in equation 1 in that they display a higher ratio of bending resistance to torsion resistance (the bending resistance is maximised). They are not as efficient with respect to torsion as the hollow ellipsoid and hollow semi-ellipsoid shapes.

Fig 15 (section $M$ ) shows that $B$. machadonis and L. vershaffeltii have the highest resistance to torsion $(\psi \mathrm{J} / \psi \mathrm{A})$ and S.minor and P. kaalae have the weakest torsional shape stiffness. T. morrisii is as efficient in response to torsion as the solid ellipse and semi-ellipse of the same $\psi \mathrm{A}$.

Figure 16 (section $\mathrm{N}$ ) shows that $K$. elegans and L. vershaffeltii have the highest resistance to torsion $(\psi \mathrm{J} / \psi \mathrm{A})$ and $P$. kaalae and S.minor have the weakest torsional shape stiffness. T. morrisii is as efficient in response to torsion as the solid ellipse and semi-ellipse of the same $\psi \mathrm{A}$.

Figure 17 (section $\mathrm{O}$ ) shows that $L$. vershaffeltii and $T$. fortunei have the highest resistance to torsion $(\psi \mathrm{J} / \psi \mathrm{A})$ and S.minor and $P$. kaalae have the weakest torsional shape stiffness. T. morrisii is more efficient in response to torsion as the solid ellipse and semi-ellipse of the same $\psi \mathrm{A}$ in section $\mathrm{O}$, but is as efficient for the other sections $\mathrm{M} \& \mathrm{~N}$.

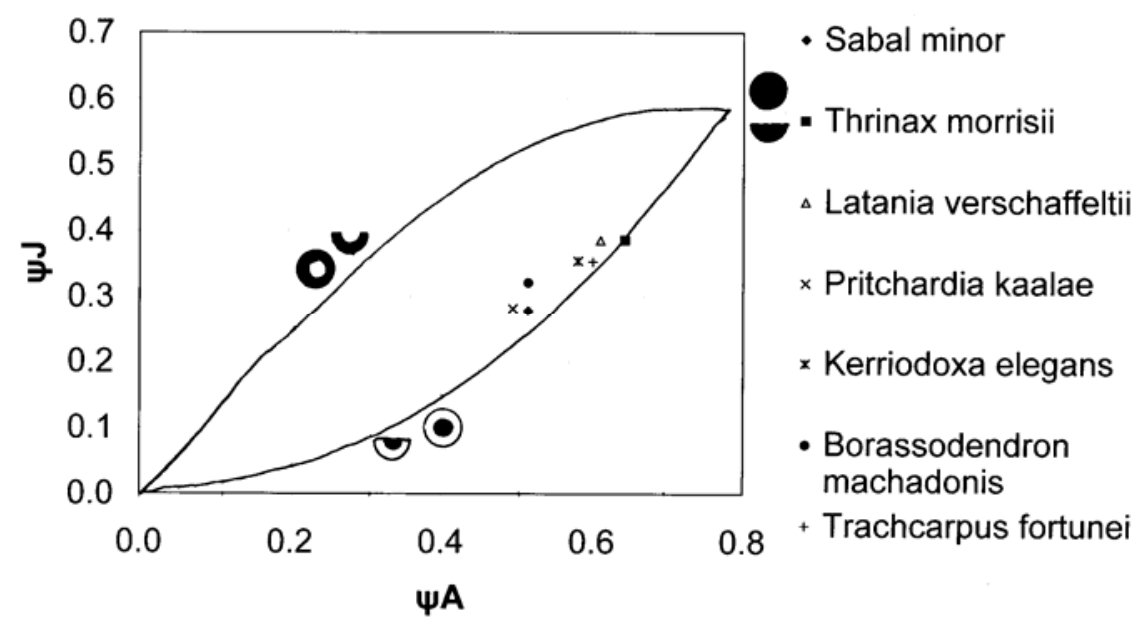

Figure 15: Section $M$ mean torsional shape stiffness for palm specimens, ellipsoid and semi-ellipsoid shapes. 


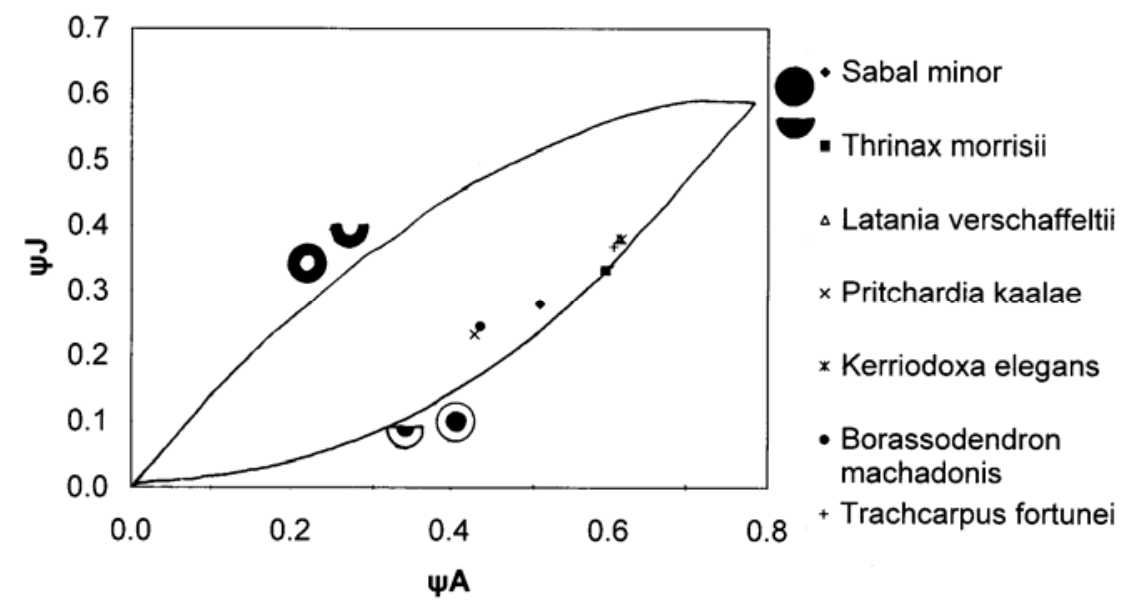

Figure 16: Section $\mathrm{N}$ mean torsional shape stiffness for palm specimens, ellipsoid and semi-ellipsoid shapes.

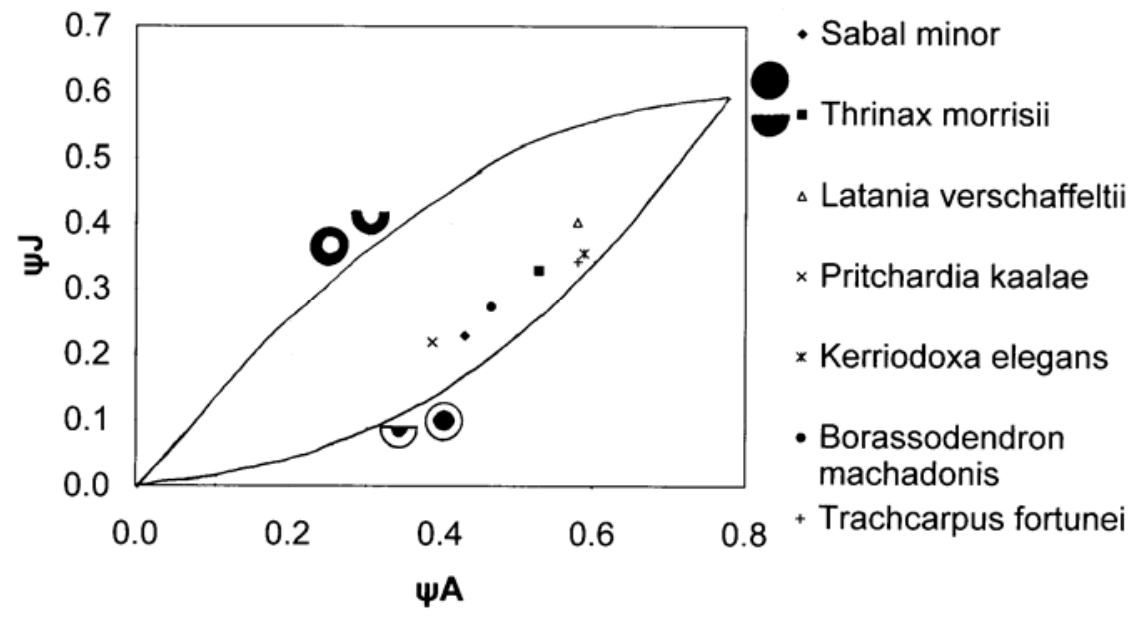

Figure 17: Section $O$ mean torsional shape stiffness for palm specimens, ellipsoid and semi-ellipsoid shapes.

\subsubsection{Conclusions: torsional shape stiffness}

K. elegans, S.minor and T. fortunei showed the greatest anomaly when compared with the ellipsoid and semi-ellipsoid shapes. For each of these palms, the central section of the petiole displayed lower resistance to torsion than either of the ends. This is different to the average palm data shown in Fig 13 where the middle section $\mathrm{N}$ is the stiffest in response to torsion.

Mean $\psi \mathrm{J} / \psi \mathrm{A}$ values for the three palms showed that $L$. vershafeltii had the highest resistance to torsion for section $\mathrm{O}$ nearest the trunk. 


\subsection{Conclusions: palm petiole bending versus torsion}

Compared with the dicots, the palms tested had relatively low torsion shape stiffness, so the palm petioles were easier to twist from a shape factor perspective. Their bending shape stiffness was also less than the dicots leading to the conclusion that the palm petioles are easier to bend from a shape factor perspective.

The shape stiffness distribution for the palms with the highest and lowest values of bending and torsional shape stiffness (K.elegans, L.vershaffeltii and P.kaalae) is shown in Figure 18. It shows the qualitative comparison between the three palms tested.

The $K$. elegans petiole displays the highest bending resistance at either end of the petiole and P.kaalae shows the lowest bending resistance in the central distal portions of the petiole, meaning that it was the most flexible when bent in these regions. L.vershaffeltii showed the highest resistance to torsion at the stem end of the petiole meaning that compared with the other two palms, it would twist the least in response to torsion.

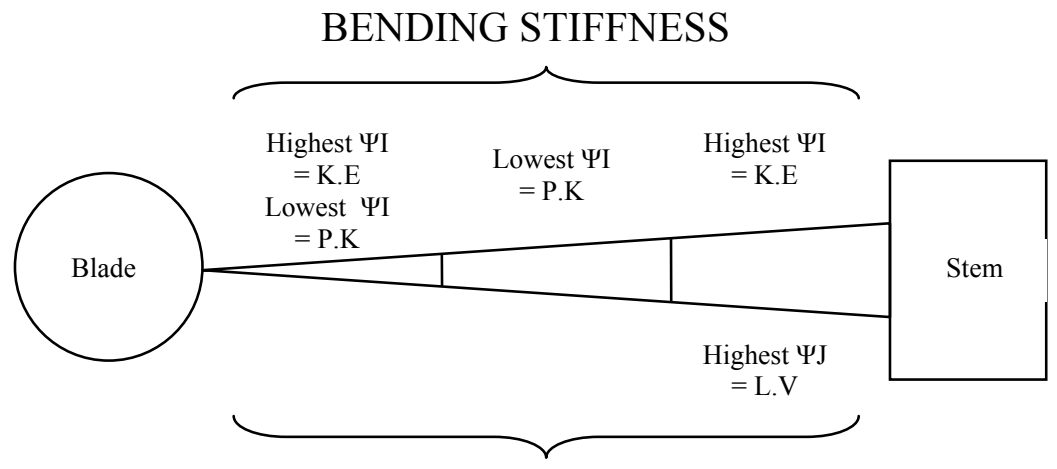

TORSION STIFFNESS

Figure 18: The comparative shape stiffness distribution along petioles of the palm petioles tested

\subsection{Petiole efficiency}

Data for this are shown in Figs 19-22 for dicots and palm sections M, N and O respectively. More specifically, the shape factors for second moment of area and polar second moment of area are plotted against each other to determine which of the palm petioles is most efficient. In this context, high efficiency means a high ratio of bending resistance to torsion resistance. 
Fig 19 shows that generally the dicots (section $\mathrm{O}$ equivalent) have equal resistance to bending and torsion and the results are similar to those for section $\mathrm{O}$ of the palm petioles (Fig 22).

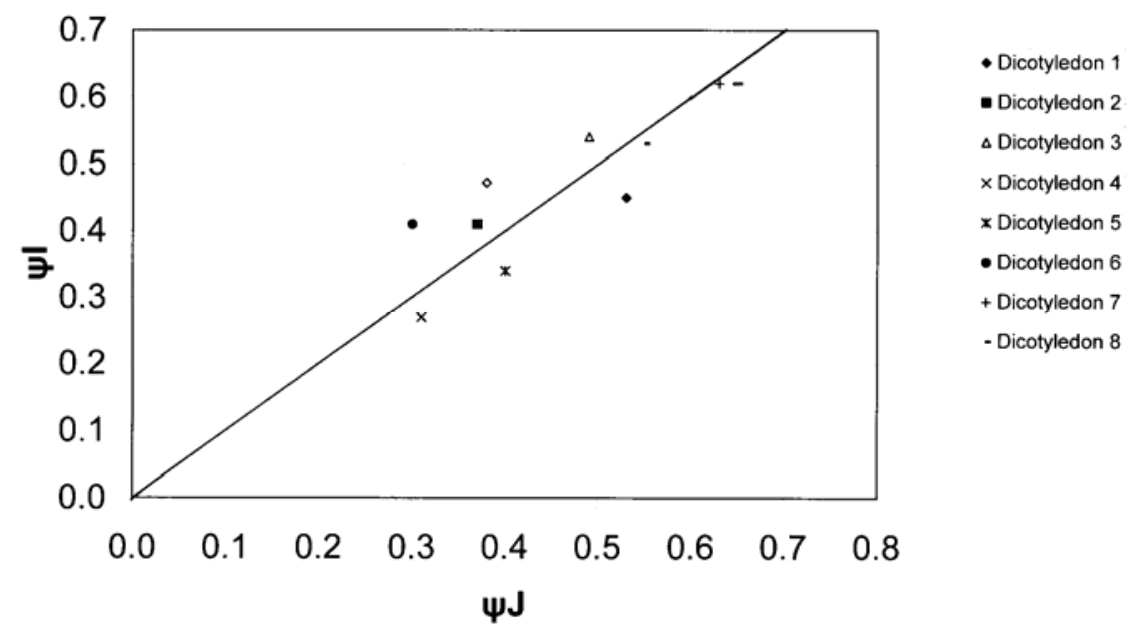

Figure 19: Dicot (equivalent to section O) mean flexural vs. torsional shape stiffness. (The line on the graph is a reference and describes where the resistance to torsion and bending are equal).

For the palms, $K$. elegans is seen to be the most efficient for each petiole section from the perspective of $\mathrm{p}$ factor (equation 1), assuming constant shear $(\mathrm{G})$ and Young's (E) moduli within and between palm species and shape factor, as this displays the highest gradient in Figures 20-22. In general, the distal portions of the palms are more resistant to bending than to torsion from a shape factor perspective. Figs 20-22 show that at the trunk end of the petiole, the shape factor resistance to bending is the same as to torsion. 


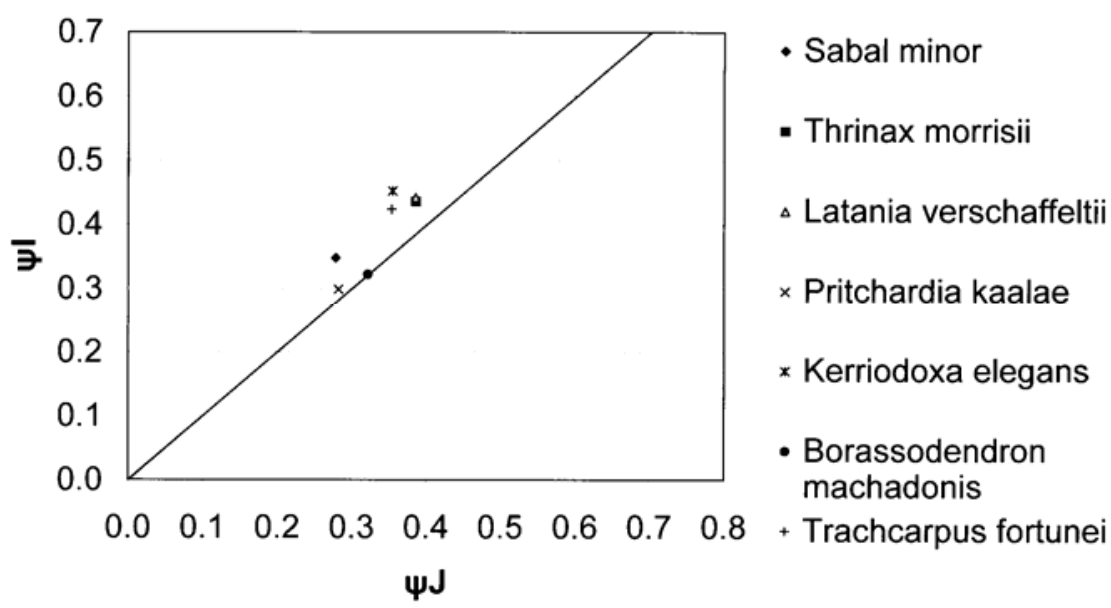

Figure 20: Section M mean flexural vs. torsional shape stiffness for palm specimens.

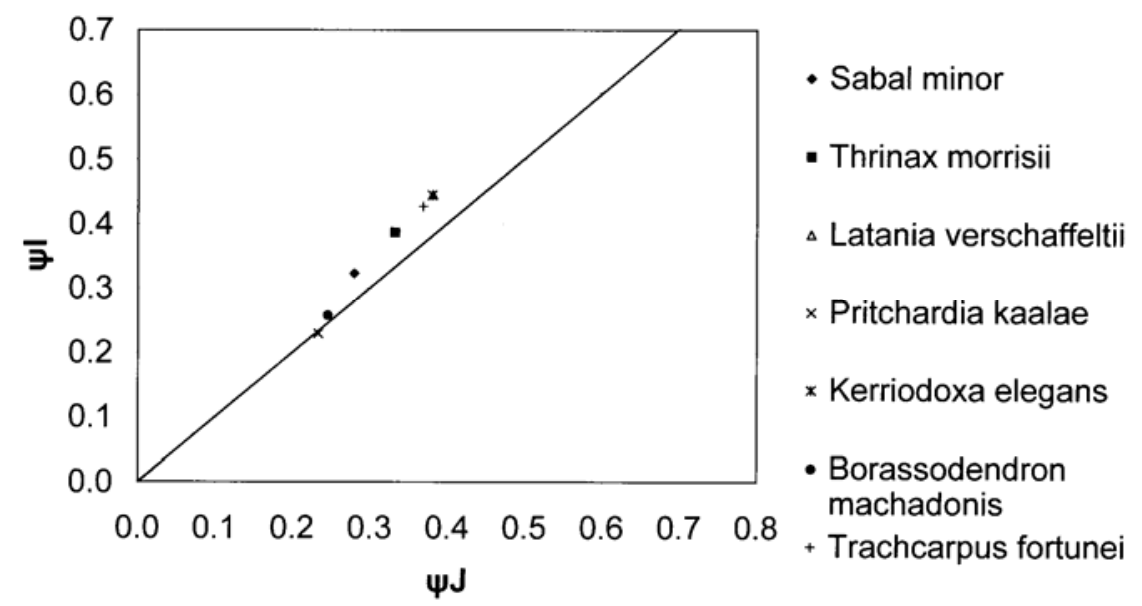

Figure 21: Section $\mathrm{N}$ mean flexural vs. torsional shape stiffness for palm specimens. 


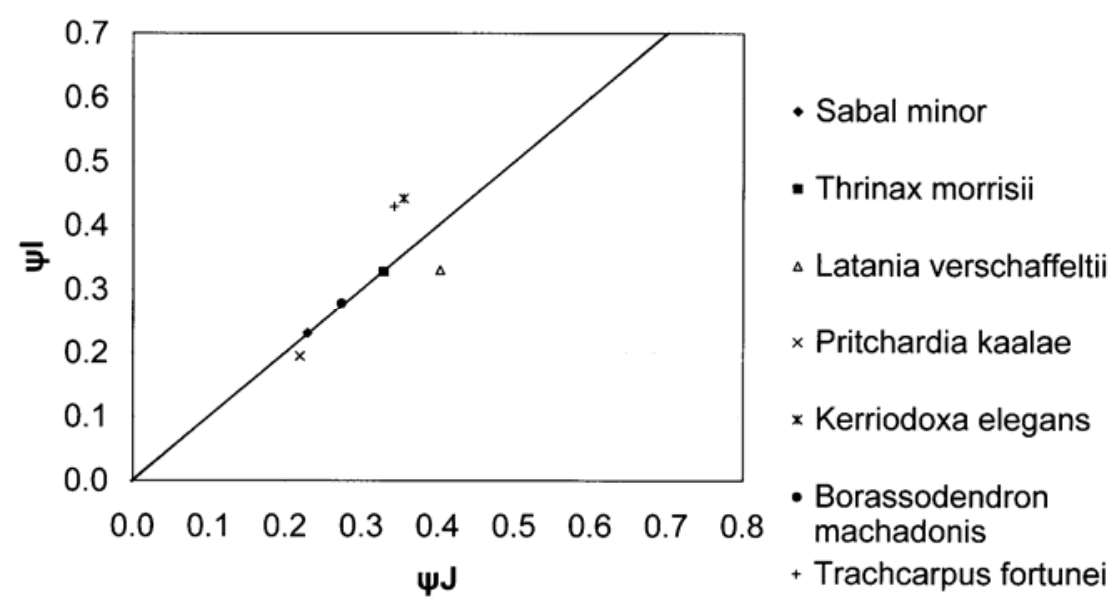

Figure 22: Section $\mathrm{O}$ mean flexural vs. torsional shape stiffness for palm specimens.

\section{General discussion}

One of the ways in which organic forms resist consistent, non-impact forces like bending is by uniform stress formation in the outer skin through adaptive growth. With reference to Mattheck [8] the maxim of uniform stress is known as a basic design rule for organic forms carrying loads. These are adapted to the forces put upon them by either 1) trial and error creating better designs accidentally, a process that is relatively slow or by 2) the adaptive growth mechanism. Organic forms like trees and bones have the ability to monitor the distribution of stresses and by using adaptive growth, change this distribution in such a way as to ideally produce a form with a uniform stress distribution at the surface.

The compressive strength of most species of wood is about fifty percent of the tensile strength although this varies greatly from species to species. The tensile strength of plant materials is remarkably high in terms of their density. Pinnate palms unlike palmate have a central strengthening rib called the midrib and according to Niklas [9], the tensile strength of the coconut palm midrib has values ranging from 0.17 to $0.3 \mathrm{GN} / \mathrm{m}^{2}$.

As the bending force on the petiole is typically downwards, material is in a compressed state on the lower surface and in a tensile state on the upper surface. The outer profile of the petiole generally becomes more ' $\mathrm{V}$ ' shaped nearest the trunk, which is where the greatest bending moment occurs on the petiole. Towards the distal end of the petiole, the abaxial surface becomes more ' $U$ ' shaped in tandem with the lesser bending moments experienced nearer the leaf. Although it has been shown that the palm petioles became more flexurally stiff (with respect to their shape only) towards the leaf blade, we have assumed that the constituents of the petiole are homogeneous. In reality, this is not the case as 
there is a complex arrangement of internal structures acting like ties and reinforcements to take into consideration.

It was noted that the shape factor plots for flexural shape stiffness, torsional shape stiffness and flexural versus torsional shape stiffness showed consistent data grouping whereby S.minor, B.machadonis and P.kaalae could be separated from the other palm species tested. To investigate the reason for these groupings, correlations were calculated between petiole length, blade dimensions, distance of petiole base from ground and trunk circumference and no significant correlation was found. The ecology of each of the palms was also checked to see if there was a relationship between the petiole properties and the degree of exposure that the palms normally encounter. Table 5 shows the physical and chemical environments of the palm species tested when in their natural habitat. On investigating the natural habitat in which these palms species grow, it was found that S.minor, B.machadonis and P.kaalae typically grow in wetter environments, thus forming a correlation with the structural grouping. From the data in Table 5, no other correlations with respect to the petiole properties could be identified.

Table 5: Natural physical and chemical environments for each palm species tested $[10]$. The temperature hardiness zones vary from $1-11\left(\leq-50^{\circ} \mathrm{F}\right.$ to $\left.\geq 40^{\circ} \mathrm{F}\right)$

\begin{tabular}{|c|c|c|c|c|c|c|}
\hline Palm Species & $\begin{array}{l}\text { Native } \\
\text { Country }\end{array}$ & $\begin{array}{l}\text { Habitat \& } \\
\text { Elevation }\end{array}$ & $\begin{array}{l}\text { Temperature } \\
\& \text { Hardiness } \\
\text { Zone }\end{array}$ & $\begin{array}{l}\text { Water } \\
\text { Require- } \\
\text { ments }\end{array}$ & $\begin{array}{l}\text { Light } \\
\text { Require- } \\
\text { ments }\end{array}$ & Soil pH \\
\hline S.minor & SE USA & $\begin{array}{l}\text { Swamps, } \\
\text { medium } \\
\text { elevation }\end{array}$ & $\begin{array}{l}\text { Very cold- } \\
\text { hardy, zone } 8\end{array}$ & $\begin{array}{l}\text { Moderate } \\
\text { to wet }\end{array}$ & $\begin{array}{l}\text { Moderate } \\
\text { to high }\end{array}$ & $\begin{array}{l}\text { Moderate to } \\
\text { high }\end{array}$ \\
\hline P.kaalae & $\begin{array}{l}\text { Hawaii - } \\
\text { Waianae } \\
\text { Mountains }\end{array}$ & $\begin{array}{l}\text { Lowland } \\
\text { moist } \\
\text { forest, } \\
400 \mathrm{~m} \\
\text { altitude }\end{array}$ & $\begin{array}{l}\text { Moderate to } \\
\text { high } \\
\text { temperatures, } \\
\text { sunny, zone } \\
10\end{array}$ & $\begin{array}{l}\text { Moist, } \\
\text { moderate, } \\
\text { well- } \\
\text { drained }\end{array}$ & $\begin{array}{l}\text { Moderate } \\
\text { to high }\end{array}$ & $\begin{array}{l}\text { Low to } \\
\text { high }\end{array}$ \\
\hline B.machadonis & Malaysia & $\begin{array}{l}\text { Rainforest, } \\
\text { medium } \\
\text { elevation }\end{array}$ & Zone 10 & Moderate & $\begin{array}{l}\text { Low to } \\
\text { moderate }\end{array}$ & $\begin{array}{l}\text { Low to } \\
\text { moderate }\end{array}$ \\
\hline T morrisii & $\begin{array}{l}\text { Carribbean } \\
\& \text { SE } \\
\text { Florida }\end{array}$ & $\begin{array}{l}\text { Low to } \\
\text { medium } \\
\text { elevation }\end{array}$ & $\begin{array}{l}\text { Great heat, } \\
\text { zone } 10\end{array}$ & $\begin{array}{l}\text { Moderate, } \\
\text { dry air }\end{array}$ & $\begin{array}{l}\text { Moderate } \\
\text { to high }\end{array}$ & $\begin{array}{l}\text { Moderate to } \\
\text { high }\end{array}$ \\
\hline$T$ fortunei & China & $\begin{array}{l}\text { Montane } \\
2400 \mathrm{~m} \\
\text { altitude }\end{array}$ & $\begin{array}{l}\text { Cold hardy, } \\
\text { zone } 7\end{array}$ & Moderate & $\begin{array}{l}\text { Moderate } \\
\text { to high }\end{array}$ & $\begin{array}{l}\text { Moderate to } \\
\text { high }\end{array}$ \\
\hline K.elegans & Thailand & $\begin{array}{l}\text { Shady } \\
\text { tropics, } \\
\text { medium } \\
\text { elevation }\end{array}$ & Zone 10 & Moderate & Low & $\begin{array}{l}\text { Moderate to } \\
\text { high }\end{array}$ \\
\hline L.vershaffeltii & $\begin{array}{l}\text { Rodriguez } \\
\text { Island, } \\
\text { middle of } \\
\text { Indian } \\
\text { Ocean } \\
\end{array}$ & $\begin{array}{l}\text { Medium } \\
\text { elevation }\end{array}$ & $\begin{array}{l}\text { Full sun, zone } \\
10\end{array}$ & Moderate & $\begin{array}{l}\text { Moderate } \\
\text { to high }\end{array}$ & Unknown \\
\hline
\end{tabular}


All of the petioles sampled were from the palm sub-family Coryphoideae of which there are three tribes; Corypheae, Phoeniceae and Borasseae. Recent molecular studies [11] and earlier morphological studies [12] suggest that the Coryphoideae represent an early radiation among the palms due to some of the early fossil records for Phoenix [13] and Thrinacineae. As a result, Coryphoideae may be one of the least specialised sub-families among the palms [14]. All of the petioles sampled are from the tribe Corypheae apart from $L$. vershaffeltii and B.machadonis which are from the tribe Borasseae. The least efficient petiole sections where the bending resistance was maximised and the torsional resistance minimised were from B.machadonis, P.kaalae and L. vershaffeltii which belong to both of these tribes so no correlation can be shown here. Perhaps this indicates that better structural efficiency with respect to shape factors does not necessarily equate to evolutionary development. The ecology of these palms was looked at in conjunction with the evolutionary aspects (Table 5) and no correlation was found. As all of these palms are still living today, the petioles are clearly efficient within the constraints of the habitat/ecological range of the individual species.

\section{Conclusions}

The petiole has to be both stiff in order to maintain the blade in a position to intercept the sun's rays as well as flexible in order to withstand the external forces of the wind, rain and snow. The vascular system also has to remain intact during torsion if the plant is to survive. A certain amount of bending and torsion ability is required to withstand the environment and also gain sunlight without breaking. Generally, it was found from a shape factor perspective that the mid and distal parts of the petioles showed greater resistance to bending than torsion meaning that their shapes were easier to twist than to bend. It must be remembered that the resistance to force values may only be attributed to shape.

Ashby et al [15] found that wood (secondary xylem), with its high value of $(E / \rho)^{1 / 2}$, is well suited to resist both bending and elastic buckling. In addition, palms, having a different structure are slightly less efficient than dicotyledonous or gymnospermous woods in bending resistance and buckling. This result correlates with what was found when the ten dicots were compared with the seven palm petioles in that, based on median averages, the petiole shapes of the dicots had a higher resistance to bending than those of the palms at each point along the palm petiole axis. This difference was greatest at the point nearest the stem and decreased along the petiole axis where at point $M$ near to where the blade meets the petiole, the flexural shape stiffness of the palm was at its greatest and similar to the dicots.

From this analysis using shape factors, an insight has been given into the mechanical behaviour of palm petioles. It is shown to be an efficient structure, economical in materials and well suited to its function. These results have consequential design implications for manmade cantilevers including sailing 
boat masts; flag poles; fishing rods; aerials; cantilevered stairs; turntable and crane arms.

\section{References}

[1] Futuyma, D.J., Evolutionary Biology, Second Edition, Sinauer Associates Inc., 1986.

[2] Gibbons, M., A pocket guide to palms, PRC Publishing, London, 2003.

[3] Pasini, D. \& Mirjalili, V., 'The optimised shape of a leaf petiole', Design and Nature III: Comparing Design in Nature with Science and Engineering. Pg 35, WITPress 2006.

[4] Burgess, S.C. \& Pasini, D, The Structural Efficiency of Trees, The University of Bristol, 2003.

[5] Milwich, M. et al, Biomimetics and Technical Textiles: Solving Engineering Problems with the Help of Nature's Wisdom, American Journal of Botany 93(10) 1455-1465, 2006.

[6] Tomlinson, P.B., The Structural Biology of Palms, First Edition, Oxford Science Publications: Oxford, 1990. Pg 10.

[7] Pasini, D., Shape Transformers for Material and Shape Selection, ASME DETC-84894, 2005.

[8] Mattheck, C. \& Tesari, I., Uniform Stress - A Design Rule for Biological Load Carriers, Institute of Materials Research II, Forschungszentrum Karlsruhe, Germany, 2003.

[9] Niklas, K.J., Plant Biomechanics: An Engineering Approach to Plant Form \& Function, First Edition, The University of Chicago Press, Chicago, 1992.

[10] Fairchild Tropical Botanic Garden, Florida, USA, website; http://www.fairchildgarden.org

[11] Asmussen, C.B. \& Chase, M.W. Coding and non-coding plastid DNA in palm systematics. American journal of botany, 88 (6): 1103-1117, 2001.

[12] Moore, H.E., The major groups of palms and their distribution. Gentes Herbarium, 11:27-141, 1973.

[13] Read, R.W \& Hickey, L.J., A revised classification of fossil palm and palmlike leaves. Taxon, 21(1):129-137, 1972.

[14] Abranson, K., 'Palm floral morphology: a review in relation to recent developments in molecular studies for palm classification', 2001.

[15] Ashby, M.F., Gibson, L.J., Wegst, U \& Olive, R., The mechanical properties of natural materials. I. Material property charts, The Royal Society, London, 1995. 